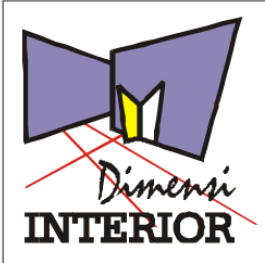

http://dimensinterior petra.acid

\title{
Perancangan Produk Interior Premium Berbasis Optimasi Penerapan Karakteristik Fisik Kayu Kelapa
}

\author{
Yunivia Anggoro | Adi Santosa | Celline Junica P. \\ Program Studi Desain Interior, Universitas Kristen Petra, Surabaya \\ Email:yunivia_12@yahoo.com
}

\begin{abstract}
ABSTRAK
Perancangan ini bertujuan untuk mengolah sumber daya alam yang jumlahnya masih berlimpah di Indonesia dan menjadikan kayu kelapa sebagai material substitusi kayu-kayu di pasaran yang mulai langka. Metode perancangan yang digunakan terdiri dari delapan tahap. Empat tahap pertama adalah memahami material, eksplorasi joint, mendesain konektor besi, dan melakukan tes terhadap kestabilan konektor tersebut. Setelah ditemukan desain konektor besi terbaik, tahapan berikutnya adalah mendesain produk, merealisasikan produk, memasarkan produk, dan melakukan evaluasi. Hasil perancangan berupa tiga set produk interior yang terdiri dari tiga belas produk mulai dari mebel, aksesoris, hingga elemen interior. Optimasi yang telah dilakukan menghasilkan produk interior yang tidak hanya menawarkan desain yang premium, namun juga memiliki ketahanan produk yang juga baik.
\end{abstract}

Kata Kunci: kayu kelapa, konektor besi, produk interior, optimasi, premium

\section{ABSTRACT}

The design aims to utilize and process the natural resources in Indonesia and use coconut wood as a substitute material for other woods that rarely found in the market. The design method consist eight main stages. The first four stages are understanding the material, exploring the wood joint, designing metal connector and testing the stability of the connectors. After finding the most suitable metal connector for the design, then the designer design and realize the product, trade the product in market and do an evaluation. The results are three set of interior products from thirteen products range including the furniture, accessories, and interior elements. The optimization produces a range of interior products with premium design and good durability as well.

Keywords: coconut wood, metal connector, interior products, optimization, premium.

\section{PENDAHULUAN}

Pohon kelapa banyak tumbuh di hutan tropis dan subtropis di berbagai negara seperti Indonesia, Malaysia, Asia Selatan, India, Amerika Selatan, dan Kepulauan Pasifik dengan suhu yang relatif stabil sebesar $53-56^{\circ} \mathrm{F}$ setiap hari [1]. Namun sayang, bahan baku kayu kelapa yang melimpah justru kurang diminati karena pengolahan untuk perbaikan kelemahan kayu kelapa sangat sulit. Beberapa kelemahan kayu kelapa antara lain mudah terserang jamur, seratnya mudah pecah, mudah lapuk jika terkena air, dan kadar air yang cukup besar [2]. Karakteristik kayu kelapa yang berbeda dengan kayu pada umumnya di pasar ini membuat perlakuan pada proses pengolahan pun berbeda. Pengetahuan mengenai pengolahan yang salah akan menurunkan kualitas kayu dan berdampak pada umur pakai suatu produk.

Perancangan desain masihlah sangat luas, dari lingkup yang paling luas yaitu tata kota, hingga yang paling kecil yaitu desain produk Desain produk memang perancangan yang paling kecil ukurannya, namun memiliki kuantitas yang justru paling banyak di pasaran [3]. Desain produk sendiri ada berbagai macam, namun perancangan kali ini spesifik pada desain produk interior (mebel, aksesoris, dan elemen interior).

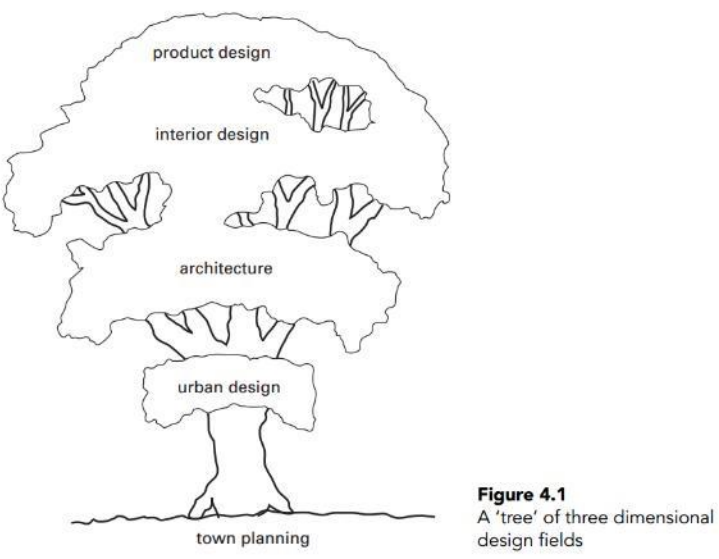

Gambar 1. A Tree of Three Dimensional Design Fields Sumber : Lawson, 2016 (54) 
Himpunan Industri Mebl dan Kerajinan Indonesia (HIMKI) menyebutkan bahwa pasar mebel domestik per Januari 2017 naik 2,76\%. BPS juga menunjukkan nilai ekspor per Januari 2017 meningkat US\$ 4 juta dari tahun sebelumnya menjadi US\$148 juta. Pada pembukaan Pameran Funiture Internasional Indonesia 2017, Presiden Jokowi akan terus mendorong upaya peningkatan produktivitas dan ekspor. Tiga alasan yang menjadi peluang baik untuk industri mebel dan kerajinan adalah bahan baku $100 \%$ berasal dari Indonesia, menyerap banyak tenaga kerja, dan menghasilkan devisa negara jika di ekspor [4].

Oleh karena itu, penting untuk dilakukan antisipasi terhadap kelemahan kayu kelapa yang sudah diketahui sejak lama dan segera dicarikan solusi yang tepat melalui kombinasi dengan material lain. Apalagi permintaan kebutuhan kayu semakin meningkat dan berbanding terbalik dengan ketersediaan bahan. Harga pengolahan kayu kelapa yang masih tergolong tinggi akan diimbangi dengan desain premium untuk kalangan menengah ke atas. Kayu kelapa yang jumlahnya sangat berlimpah ini memiliki peluang menjadi material alternative pengganti bila diolah dengan benar, khususnya pada pembuatan produk interior premium.

\section{METODE PERANCANGAN}

Metode perancangan dibuat menyesuaikan dengan tahapan dan kebutuhan perancangan yang terdiri dari 8 tahap. Diagram metode perancangan tersebut disusun secara berurutan dan digambarkan sebagai berikut:

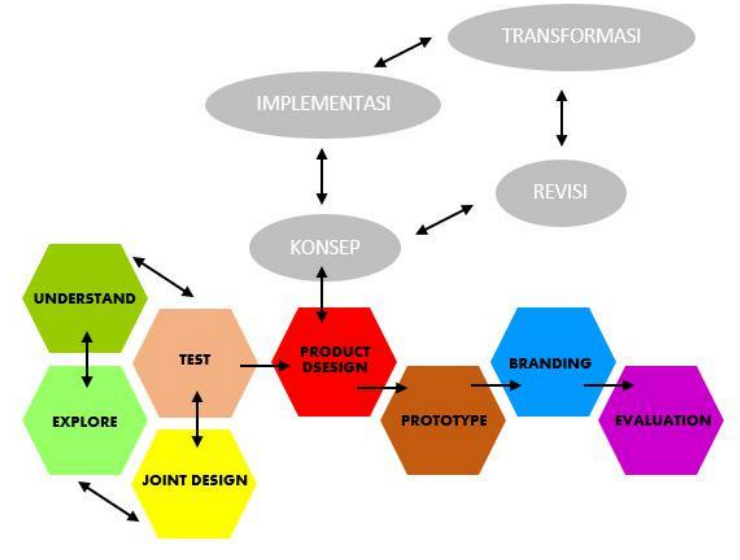

Gambar 2. Metode Perancangan

\section{A. Understand}

Mencari referensi dan mempelajari lebih mendalam tentang kayu kelapa secara luas. Pemahaman berlanjut lebih spesifik mengenai sifat fisik kayu kelapa hingga ditemukan kesimpulan mengenai karakteristik kayu kelapa.

\section{B. Explore}

Mencari data dari penelitian sebelumnya mengenai cara untuk mengatasi kelemahan kayu kelapa menggunakan model sambungan. Model sambungan yang ada dianalisa kelemahan dan kelebihannya untuk dipilih model sambungan yang terbaik untuk dikembangkan.

\section{Joint Design}

Sebekum merancang produk interior berbahan kayu kelapa, yang terlebih dahulu didesain adalah sambungan konstruksi. Sambungan konstruksi merupakan kunci utama pada perancangan karena kayu kelapa memiliki masalah fisik yang harus terlebih dahulu diatasi agar menghasilkan desain yang optimal.

\section{Test}

Desain sambungan konstruksi yang telah dibuat kemudian masuk ke dalam tahap pengujian fisik untuk mengetahui secara akurat ketahanan sambungan konstruksi. Desain sambungan dikembangkan dan diperbaiki sesuai kebutuhan hingga ditemukan satu desain yang paling optimal untuk diterapkan pada perancangan.

Test dilaksanakan berdasarkan metode penelitian eksperimen yang dipersiapkan dalam jangka waktu tertentu. Eksperimen adalah observasi yang dilakukan menggunakan kondisi buatan (artificial condition) yang dibuat dan diatur oleh peneliti. Maka dapat disimpulkan bahwa penelitian eksperimen adalah penelitian yang dilakukan dengan membuat manipulasi terhadap objek yang diteliti di bawah kontrol peneliti. Lebih spesifik, eksperimen yang dilakukan termasuk ke dalam jenis eksperimen perbandingan. Eksperimen perbandingan (comparative experiment) merupakan eksperimen yang dilakukan dengan membandingkan perlakuan-perlakuan (dalam hal ini joint-joint kayu kelapa pada beberapa tingkatan kadar air) dan membandingkan pengaruh perlakuan tersebut terhadap satu populasi yang dipilih [5].

\section{E. Product Design}

Setelah menemukan desain konektor final, tahap selanjutnya adalah mengembangkan bentukan dan jenis produk interior yang akan dirancang. Perancangan dimulai dari tahap penentuan konsep, pengaplikasian konsep pada desain, transformasi desain, dan diakhiri tahap revisi/perbaikan setelah mendapatkan masukan dari berbagai pihak. Desain divisualisasikan ke dalam sketsa, maket studi, dan render agar mendapat gambaran yang jelas sebelum masuk ke pembuatan prototype. Desain dilengkapi dengan gambar kerja yang detail agar memudahkan pengerjaan dan mengurangi kemungkinan kesalahan dalam produksi.

\section{F. Prototype}

Gambar kerja dari desain final kemudian direalisasikan dalam prototype 1: 1 sesuai dengan spesifikasi yang diinginkan. Proses pengerjaan dipantau secara rutin dan teliti untuk memastikan kualitas produk yang dihasilkan memenuhi standar produk interior premium.

\section{G. Branding}

Setelah proses pembuatan prototype dimulai, branding produk mulai dipersiapkan. Mulai dari nama masingmasing produk, nama brand, desain brand, hingga cara pemasaran produk. Branding dilakukan secara offline (brosur, katalog, tag, poster) dan online (berbagai media sosial). Diharapkan melalui branding yang kuat, proses pengenalan produk akan lebih cepat dan luas. 


\section{H. Evaluation}

Tahap yang terakhir adalah mengevaluasi kelebihan dan kekurangan produk untuk nantinya dikembangkan pada perancangan selanjutnya. Evaluasi dilakukan melalui uji oleh dosen, pameran, dan respon pasar terhadap hasil perancangan.

\section{TINJAUAN PUSTAKA}

\section{A. Kayu Kelapa}

Pohon kelapa yang memiliki nama ilmiah Cocos nucifera $L$. adalah jenis pohon daerah tropis yang termasuk palmaceae dan golongan monocotyledoneae. Pohon kelapa banyak tumbuh liar di kawasan pantai dan dapat juga dibudidayakan (Jawa, Sumatera, Sulawesi dengan kualitas A, dan Kalimantan). Pohon kelapa yang sudah ditebang harus segera dikeluarkan dari kebun agar tidak menjadi sarang kumbang gerek.

Pohon kelapa berdiameter $25-40 \mathrm{~cm}$ dengan tinggi berkisar antara 15-40 m. Pertumbuhan batang kayu kelapa lurus ke atas dan tidak memiliki cabang, barulah di ujung batang terdapat titik tumbuh untuk membentuk daun, bunga, dan batang. Sedangkan pertumbuhan batang kayu kelapa ke samping (diameter) akan berhenti pada usia 3-4 tahun [6].

Kayu kelapa memiliki berat jenis rata-rata $0,74 \mathrm{gr} / \mathrm{cm} 3$ dan termasuk dalam kelas kuat II dengan berat jenis antara 0,90-0,40 gr/cm3. Keawetan alami kayu didukung oleh zat-zat yang terkandung di dalamnya yang berperan sebagai racun bagi pengerusak kayu dan kayu kelapa termasuk dalam kelas awet III [7].

Tabel 1. Perbandingan Berat Jenis Kayu [7].

\begin{tabular}{|c|c|c|c|}
\hline Jenis Kayu & Berat Jenis & Kelas Kuat & Kelas Awet \\
\hline Jelutung & 0.43 & III-IV & V \\
\hline Meranti & 0.51 & III-IV & III-IV \\
\hline Nyatoh & 0.60 & II-III & IV \\
\hline Sungkai & 0.63 & II-III & III-V \\
\hline Keruing & 0.70 & II & II \\
\hline Glugu & 0.74 & II-III & III \\
\hline Merbau & 0.79 & I-II & I-II \\
\hline Jati & 0.88 & II & II \\
\hline
\end{tabular}

Tabel 2. Klasifikasi Keawetan Kayu di Indonesia [9].

\begin{tabular}{|l|c|c|c|c|c|}
\hline \multicolumn{1}{|c|}{ Kelas Awet } & I & II & III & IV & V \\
\hline $\begin{array}{l}\text { Selalu berhubungan } \\
\text { dengan tanah } \\
\text { lembab }\end{array}$ & 8 th & 5 th & 3 th & $\begin{array}{c}\text { Sangat } \\
\text { pendek }\end{array}$ & $\begin{array}{c}\text { Sangat } \\
\text { pendek }\end{array}$ \\
\hline $\begin{array}{l}\text { Hanya dipengaruhi } \\
\text { cuaca, tetapitetap } \\
\text { dijaga agar tidak } \\
\text { terendam air dan } \\
\text { tidak kekurangan } \\
\text { udara }\end{array}$ & 20 th & 15 th & 10 th & $\begin{array}{c}\text { Beberapa } \\
\text { tahun }\end{array}$ & $\begin{array}{c}\text { Sangat } \\
\text { pendek }\end{array}$ \\
\hline $\begin{array}{l}\text { Di bawah atap, } \\
\text { tidak berhubungan } \\
\text { dengan tanah } \\
\text { lembab, dan tidak } \\
\text { kekurangan udara }\end{array}$ & terbatas & terbatas & $\begin{array}{c}\text { Tamgat } \\
\text { lama }\end{array}$ & $\begin{array}{c}\text { Beberapa } \\
\text { tahun }\end{array}$ & Pendek \\
\hline $\begin{array}{l}\text { Seperti di atas tetapi } \\
\text { dipelihara dengan } \\
\text { baik dan dicat }\end{array}$ & Terbatas & $\begin{array}{c}\text { Tak } \\
\text { terbatas }\end{array}$ & $\begin{array}{c}\text { Tak } \\
\text { terbatas }\end{array}$ & 20 th & 20 th \\
\hline $\begin{array}{l}\text { Serangan rayap } \\
\text { tanah }\end{array}$ & Tidak & Jarang & Cepat & $\begin{array}{c}\text { Sangat } \\
\text { cepat }\end{array}$ & $\begin{array}{c}\text { Sangat } \\
\text { cepat }\end{array}$ \\
\hline $\begin{array}{l}\text { Serangan bubuk } \\
\text { kayu } \\
\text { kering }\end{array}$ & Tidak & $\begin{array}{c}\text { Tidak } \\
\text { berarti }\end{array}$ & $\begin{array}{c}\text { Hampir } \\
\text { berarti }\end{array}$ & $\begin{array}{c}\text { Tidak } \\
\text { cepat }\end{array}$ & $\begin{array}{c}\text { Sangat } \\
\text { cepat }\end{array}$ \\
\hline
\end{tabular}

Berdasarkan data berat jenis kayu kelapa dengan angka $0,74 \mathrm{gr} / \mathrm{cm} 3$, kayu ini termasuk dalam kelas bobot kayu agak berat ${ }^{[8]}$. Kayu kelapa memiliki kadar air yang bervariasi pada satu pohon yang sama. Semakin ke ujung, kadar air pada kayu kelapa akan semakin banyak. Kadar air pada bagian pangkal $\pm 50 \%$ dan pada bagian ujung $\pm 400 \%$. Kadar air juga akan semakin bertambah mendekati bagian tengah kayu kelapa. Jadi, bagian kayu dengan kekuatan paling maksimal terletak pada bagian terluar dan pangkal. Kadar air pemakaian kayu berbedabeda berdasarkan pemakaiannya sehingga harus disesuaikan dengan standar pada tabel acuan [6].

Tabel 3. Batas Kadar Air Kayu untuk Setiap Tujuan Pemakaian [8].

\begin{tabular}{|c|c|}
\hline Kadar Air & Tujuan Pemakaian \\
\hline $\mathbf{2 0 \%}$ & $\begin{array}{c}\text { Kayu terhindar dari serangan jamur pewarna dan } \\
\text { bubuk kayu basah }\end{array}$ \\
\hline $\mathbf{1 7} \mathbf{- 1 6 \%}$ & Pintu luar, alat pertanian, kursi kebun \\
\hline $\mathbf{1 5 \%}$ & Kayu untuk kegunaan umum \\
\hline $\mathbf{1 3}-\mathbf{1 1 \%}$ & $\begin{array}{c}\text { Mebel kayu, pintu dalam ruangan yang kadang } \\
\text { dipanasi/berpendingin }\end{array}$ \\
\hline $\mathbf{1 2}-\mathbf{1 0 \%}$ & $\begin{array}{c}\text { Produk kayu dan lantai kayu dalam ruangan yang terus } \\
\text { menerus dipanasi/berpendingin }\end{array}$ \\
\hline $\mathbf{1 0}-\mathbf{9 \%}$ & $\begin{array}{c}\text { Produk kayu yang dekat dengan sumber panas atau } \\
\text { berpendingin }\end{array}$ \\
\hline $\mathbf{9 - 7 \%}$ & Lantai kayu yang di atasnya ada pemanas \\
\hline $\mathbf{7 - 5} \%$ & Peralatan musik \\
\hline $\mathbf{1 0}-\mathbf{8} \%$ & Bahan kemasan \\
\hline
\end{tabular}

Setelah kayu mengalami pengeringan, maka kadar air akan berkurang (menyusut) dan berpengaruh pada bentuk fisik kayu. Penyusutan pada kayu dapat menimbulkan kerusakan apabila kurang berhati-hati dalam pengolahannya. Macam-macam kerusakan yang diakibatkan oleh penyusutan kayu adalah pecah ujung (end checks), pecah permukaan (surface checks), pecah pada ujung hingga menjalar sepanjang papan, retak dalam kayu (honeycombing), casehardening, melengkung pada arah lebar kayu (cupping), melengkung pada arah panjang kayu (bowing), menggelinjang (twist), dan perubahan bentuk penampang kayu (diamonding) [9].

\section{B. Premium}

Konsumen sendiri sebagai pelaku utama memiliki pandangan yang berbeda-beda mengenai bagaimana sebuah produk dapat dikatakan premium. Hasil survey yang dilakukan Nielsen mengatakan sebagian besar responden mengatakan bahwa produk premium tidak hanya dilihat dari segi harga saja. Sebanyak 54\% responden menentukan produk premium dari segi kualitas dan kinerja yang sangat baik. Sedangkan $46 \%$ responden melihat produk premium dari segi fungsi dan kinerjanya. Fitur lain yang menjadikan sebuah produk premium adalah desain superior, brand terpercaya, pengalaman konsumen, serta kelebihan yang tidak dimiliki pada produk lainnya (38\% dan $37 \%$ ). Pada presentase yang lebih rendah, terdapat beberapa fitur lainnya seperti lokasi yang memang dikenal memiliki kualitas unggul, harga mahal, dibuat dengan keahlian tertentu, hanya tersedia untuk kalangan tertentu, dan langka [10]. 
Dari berbagai persepsi mengenai produk premium, dipilih beberapa fitur yang nantinya akan dijadikan standar perancangan sekaligus agar produk bisa dipasarkan sesuai target. Beberapa fitur yang harus dipenuhi pada produk adalah desain, kualitas, fungsi, dan dibuat dengan keahlian khusus. Produk akan diproduksi terbatas dalam rangka menjaga eksklusivitas produk dan diharapkan dapat memberi pengalaman baru untuk pengguna sehingga nantinya dapat menjadi brand baru dalam industri produk interior.

\section{EKSPERIMEN DAN PEMBAHASAN}

Eksperimen yang dilakukan adalah percobaan untuk mengetahui pengaruh perubahan kadar air kayu terhadap bentuk fisik kayu kelapa, dalam hal ini bentuk fisik akan berpengaruh pada kestabilan joint yang telah dibuat. Kadar air kayu dikontrol dengan mengatur suhu oven pengering, dalam hal ini sebagai gambaran suhu lingkungan tempat produk akan diletakkan. Sebelum melakukan eksperimen, konektor besi dan komponen kayu kelapa dibuat terlebih dahulu sebagai sampel eksperimen. Kemudian disiapkan alat dan bahan yang dibutuhkan untuk mendukung eksperimen.
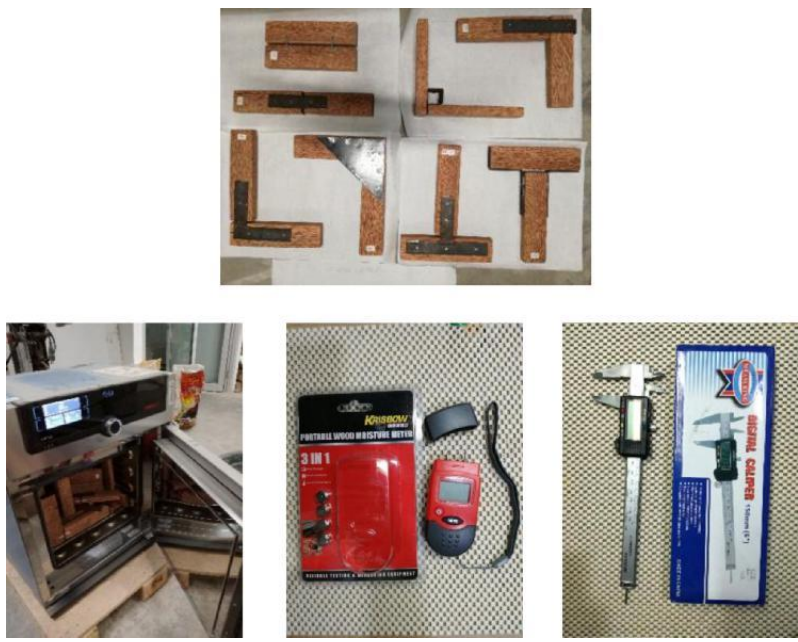

Gambar 3. Sampel dan Alat Pendukung Eksperimen

Data detail mengenai sampel dicatat pada tabel untuk kemudian dibandingkan antara data sebelum dan sesudah eksperimen. Setelah membandingkan kedua tabel tersebut, terdapat perubahan pada sampel akibat proses pengeringan.

Tabel 4. Tabel Perubahan pada Sampel

Tabel 4. Tabel Perubahan pada Sampel
\begin{tabular}{|c|c|c|c|c|c|}
\hline \multirow{3}{*}{ Kode } & Selisih Dimensi ( PxLxT/mm ) & Selisih Kadar Air (\%) \\
\cline { 2 - 6 } & $\begin{array}{c}\text { Komponen } \\
1\end{array}$ & $\begin{array}{c}\text { Komponen } \\
2\end{array}$ & Jarak & $\begin{array}{c}\text { Komponen } \\
1\end{array}$ & $\begin{array}{c}\text { Komponen } \\
2\end{array}$ \\
\hline A1 & $2 \times 1 \times 1$ & $2 \times 1 \times 1$ & 1,0 & 6 & 14 \\
\hline A2 & $2 \times 1 \times 1$ & $2 \times 1 \times 1$ & 0,2 & 5 & 6 \\
\hline B1 & $2 \times 1 \times 2$ & $2 \times 2 \times 1$ & 0,9 & 13 & 10 \\
\hline B2 & $2 \times 1 \times 3$ & $2 \times 2 \times 2$ & 1,0 & 11 & 9 \\
\hline B3 & $2 \times 1 \times 1$ & $2 \times 1 \times 1$ & 0,8 & 8 & 11 \\
\hline C1 & $2 \times 1 \times 2$ & $2 \times 1 \times 2$ & 1,0 & 13 & 7 \\
\hline D1 & $2 \times 3 \times 1$ & $2 \times 1 \times 1$ & 0,8 & 7 & 7 \\
\hline D2 & $2 \times 1 \times 1$ & $2 \times 1 \times 1$ & 1,0 & 7 & 7 \\
\hline
\end{tabular}

Komponen mengalami penyusutan antara 1-2 mm dan membuat jarak antar komponen yang semula $5 \mathrm{~mm}$ menjadi 0,8-1 mm. Penyusutan menyebabkan perubahan pada fisik kayu, yaitu twisting dan retak rambut pada ujung (end checks) atau permukaan kayu (surface checks). Selain itu, kadar air kayu menurun hingga 50\% dari keadaan awal 16-22 \% menjadi 8-12 $\%$.

\section{KONSEP DESAIN}

Konsep desain bermula dari ditemukannya permasalahan dan hasil analisa alternatif solusi. Solusi yang diterapkan adalah membuat desain eksklusif yang diproduksi terbatas untuk kalangan tertentu, dalam upaya untuk mengimbangi cost produksi. Konsep desain adalah "premium" yang diaplikasikan ke dalam 5 aspek. Kelima aspek tersebut yaitu membuat desain yang eksklusif dan ergonomis, menggunakan bahan baku berkualitas, fungsional, dibuat dengan keahlian khusus dan diproduksi secara terbatas. Sedangkan style yang digunakan adalah mid-century. Beberapa ciri desain mid-century adalah pemilihan material utama kayu, finishing natural, simple, garis-garis tegas, dan [11]. Kesan yang ingin ditimbulkan pada produk adalah tropis dan diterapkan pada pemilihan finishing kayu dan warna spons dudukan.

Kesan tropis juga sejalan dengan branding produk "Pesona-Pengisi Interior Olahan Kelapa" yang mengangkat potensi material daerah tropis, dalam hal ini adalah kayu kelapa. Simbol pohon kelapa dimasukkan ke dalam brand untuk memudahkan konsumen memahami bahwa produk interior yag dibuat menggunakan material utama kayu kelapa. Warna brand menggunakan warna emas dan hitam untuk menyelaraskan dengan kesan premium produk interior yang ditawarkan.

Produk yang ditawarkan oleh brand "PESONA" adalah tiga set produk interior yang terdiri dari mebel, aksesoris, dan elemen interior. Ketiga set tersebut memiliki nama seri "Pesona Budaya" untuk mebel ruang tamu, "Pesona Wisata" untuk mebel teras dan "Pesona Flora" untuk aksesoris serta partisi ruangan.

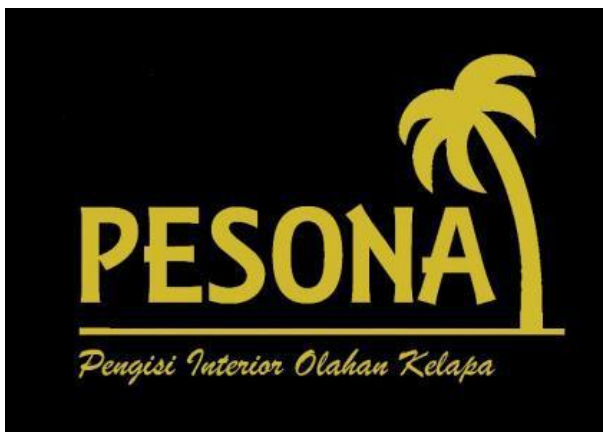

Gambar 4. Logo "PESONA"

\section{DESAIN AKHIR}

Produk-produk interior yang telah melalui proses transformasi desain hingga ditemukan desain terbaik sebagai desain terpilih untuk dipasarkan. Terdapat 13 desain terpilih yang terbagi ke dalam tiga kategori set produk sebagai keluaran brand "PESONA". 


\section{A. Pesona Budaya}

Kebersamaan merupakan norma budaya yang melekat untuk mempererat kekeluargaan. Jadi, produk dari "Pesona Budaya" adalah satu set mebel (lima produk) untuk diletakkan di ruang keluarga. Diharapkan keluaran produk dapat memenuhi kebutuhan pengguna sehingga menjadikan ruang keluarga menjadi tempat yang nyaman untuk berkumpul seluruh anggota keluarga.

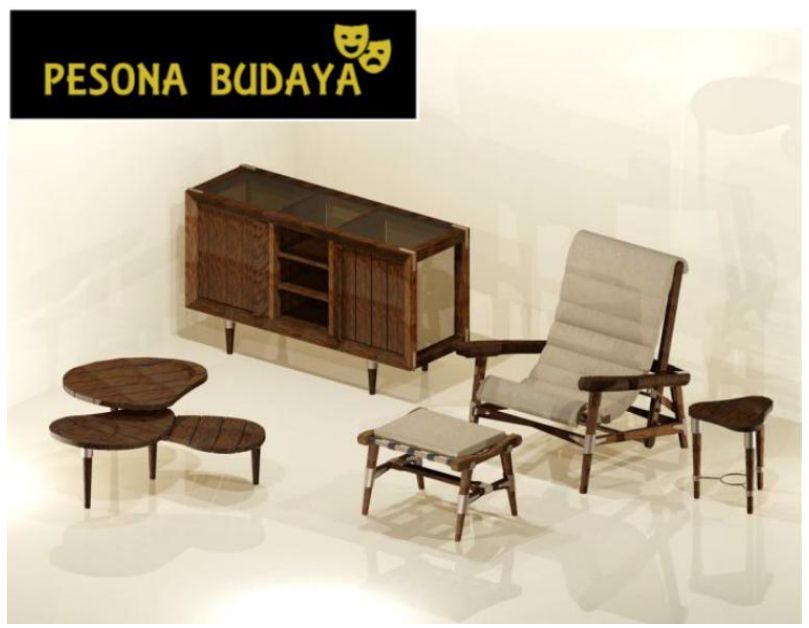

Gambar 5. Satu Set Produk dari "Pesona Budaya"

\section{B. Pesona Wisata}

Pantai merupakan salah satu destinasi wisata yang paling sering dikunjungi untuk bersantai. Jadi, produk dari "Pesona Wisata" terdiri dari lima produk yang dapat diletakkan di area teras. Hasil jadi produk diharapkan mampu memberikan rasa nyaman bagi pengguna yang ingin bersantai di teras.
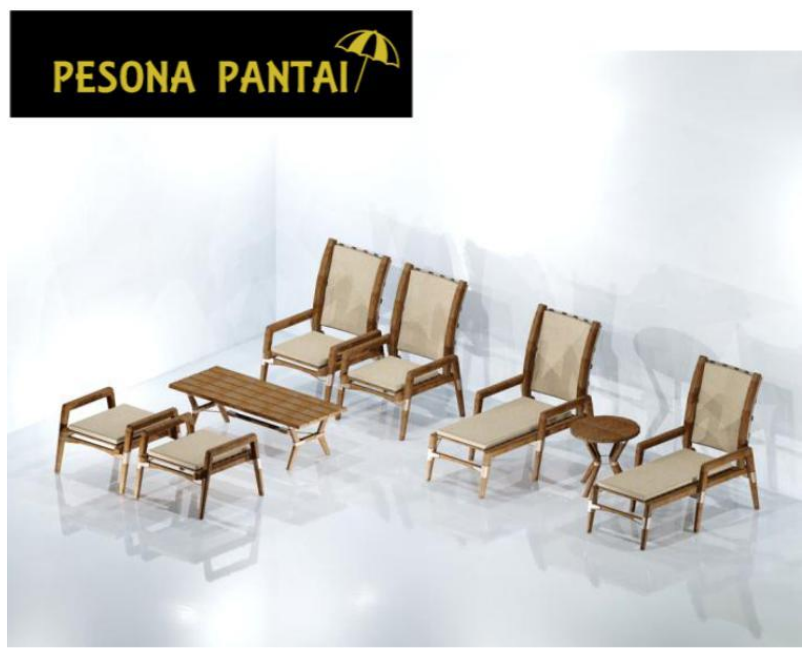

Gambar 6. Satu Set Produk dari "Pesona Wisata"

\section{Pesona Flora}

Bunga merupakan simbol keindahan yang serng digunakan untuk mempercantik ruangan secara visual. Jadi, produk dari "Pesona Flora" terdiri dari tiga produk yaitu partisi dan aksesoris untuk mempercantik interior ruangan. Produk-produk dari seri ini diharapkan dapat memanjakan visual pengguna dalam ruangan.

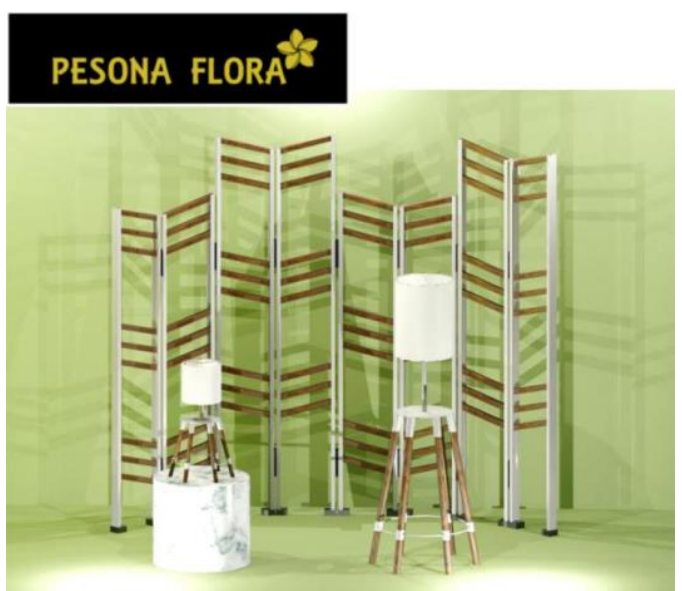

Gambar 7. Satu Set Produk dari "Pesona Flora"

\section{PROSES PRODUKSI DAN PROTOTYPE}

Produk terpilih yang dibuat prototype $1: 1$ adalah tiga buah mebel dari seri Pesona Budaya. Ketiga mebel tersebut adalah armchair, ottoman, dan side table.

Proses produksi mebel secara berurutan yaitu pengeringan material, meratakan dimensi kayu, mencetak bentuk, pemotongan kayu, bubut kayu, membuat cekungan meja, penghalusan, pembuatan joint mortise tenon, perakitan sementara, pembuatan konektor besi, finishing, dan perakitan. Sedangkan proses produksi spons duduk berurutan dimulai dari pemotongan webbing, jahit webbing, pemotongan dan pengeleman spons, pemotongan fabric, dan diakhiri dengan menjahit velcrow.
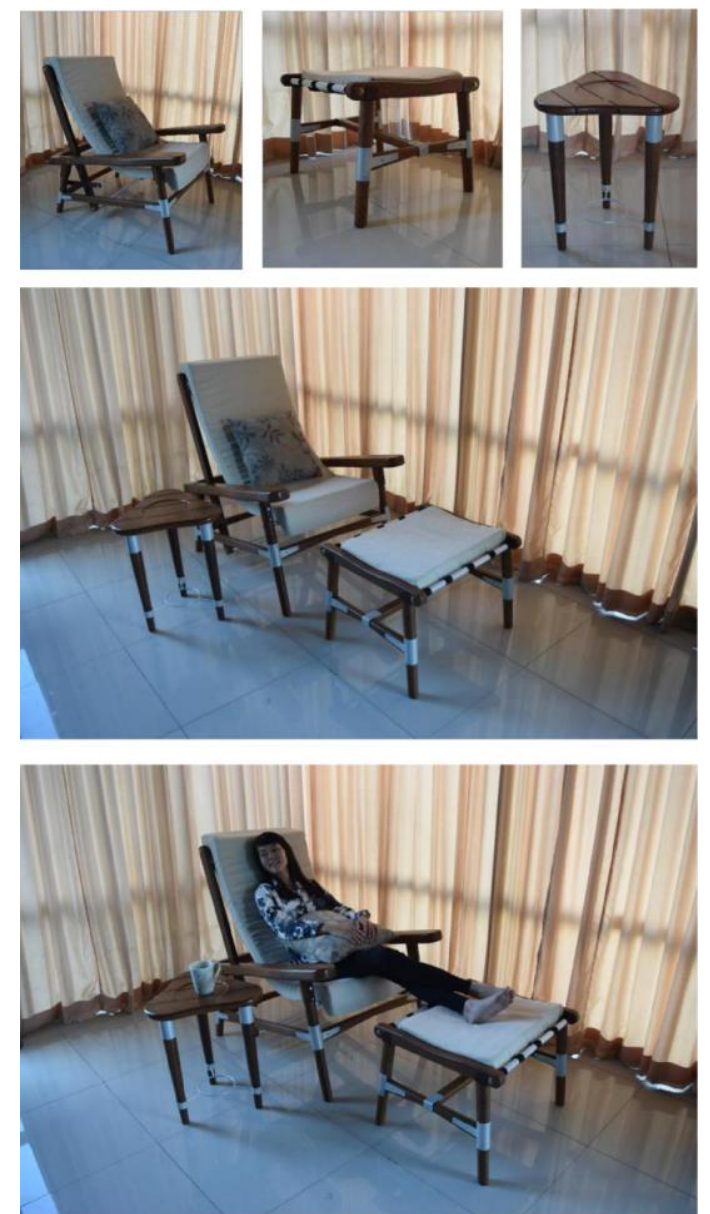

Gambar 8. Penggambaran prototype dengan pengguna pada ruang 


\section{SIMPULAN}

Desain yang berawal dari pemilihan material harus didasari dengan pemahaman tentang karakteristik material yang dipakai. Salah satu karakteristik kayu kelapa yang sekaligus menjadi kelemahan adalah serat-serat kayu kelapa yang menyerupai lidi dan pendek. Serat kayu kelapa yang seperti ini membuat desain menjadi terbatas karena kayu tidak bisa dibuat lengkung. Pemakaian plat besi sebagai konektor memberikan dampak positif dalam mengatasi permasalahan susut kayu kelapa. Konektor tidak hanya berfungsi sebagai konstruksi, namun juga sebagai nilai estetika.

Sebaiknya dilakukan pengembangan lebih lanjut mengenai macam-macam konektor yang digunakan agar bentukan desain bisa semakin bebas dan dinamis. Pembuatan konektor besi membutuhkan ketelitian dan keahlian khusus karena membutuhkan kepresisian agar bisa mengikat antar komponen kayu dengan pas. Kontrol terhadap kualitas dan pengerjaan produksi juga harus turin dilakukan agar kualitas produk yang ditawarkan sesuai dengan target pasar yang diharapkan.

\section{REFERENSI}

[1] Sejarah dan Asal Usul Pohon Kelapa I Iklim yang Tepat agar Kelapa Bisa Tumbuh dengan Baik. (n.d). Diakses 9 Oktober, 2017, dari http://www.coconese.net/

[2] Phebryanti, Sarah. (2015). Kayu Kelapa Sebagai Bahan Alternatif untuk Mebel di Area Public Rumah Tinggal. 3(1), 53-56. Diakses 9 Oktober, 2017, dari http://studentjournal.petra.ac.id/index.php/desaininterior/article/view/2942

[3] Lawson, Bryan. (2006). How Designers Thnik. London: The Architectural Press Ltd

[4] Melani, Agustina. (2017, Maret). 3 Potensi Industri Furnitur untuk Indonesia. Liputan6. Diakses 8 Desember, 2017, dari http://bisnis.liputan6.com/read/2882681/3-potensi-industri-furnituruntuk-indonesia

[5] Nazir, Moh. (2005). Metode Penelitian. Bogor: Ghalia Indonesia.

[6] Kusyanto, Mohhamad. (2011). Kajian Material Kayu Glugu Sebagai Bahan Bangunan. Diakses 9 Oktober, 2017, dari http://ejurnal.unisfat.ac.id/index.php/TATAL/article/view/90

[7] Indrosaptono, D., Sukawi., \& Indraswara, M. S. (2014). Kayu Kelapa (Glugu) Sebagai Alternatif Bahan Konstruksi Bangunan. Diakses 2 Maret, 2018, dari https://ejournal.undip.ac.id/index.php/modul/article/view/6550

[8] Basri, Efrida.. (2012). Modul Bimbingan Teknis Pengeringan Kayu. Retrieved 6 Januari, 2018 from www.fordamof.org/files/pengeringan-kayu-efrida-basri.pdf

[9] Dumanauw, J. F. (2001). Mengenal Kayu. Yogyakarta: PT Kanisius (Anggota IKAPI).

[10]Deeper Than Dollars: Global Perceptions About Premim Product. (2016). Diakses 6 Januari, 2017, dari http://www.nielsen.com/id/en/insights/news/2016/deeper-thandollars-global-perceptions-about-premium-products.html

[11]Putra, Adhitya. (2017, November). Mengenal Gaya Mid-Century Modern dan Tips Penerepannya di Hunian. Diakses 21 Juni, 2018 dari http://www.rumahhokie.com/beritaproperti/mengenal-gayamid-century-modern-dan-tips-penerapannya-di-hunian/ 